\title{
The Force of the Intoxic - The Addict Saint
}

\author{
Rob Shields \\ University of Alberta
}

Abstract: This paper sets out to discover the intangible complement of toxic material that is felt through its effect. It begins from the qualities of the toxic and considers the historical conception of the toxin as an external substance that brings benefit and illumination but is lethal in larger doses. The pursuit of transcendence is a common benefit illustrated in the addicted and the saintly. They share a pursuit of the 'intoxic,' a force that mediates between the body and transcendence, whether spiritual or social.

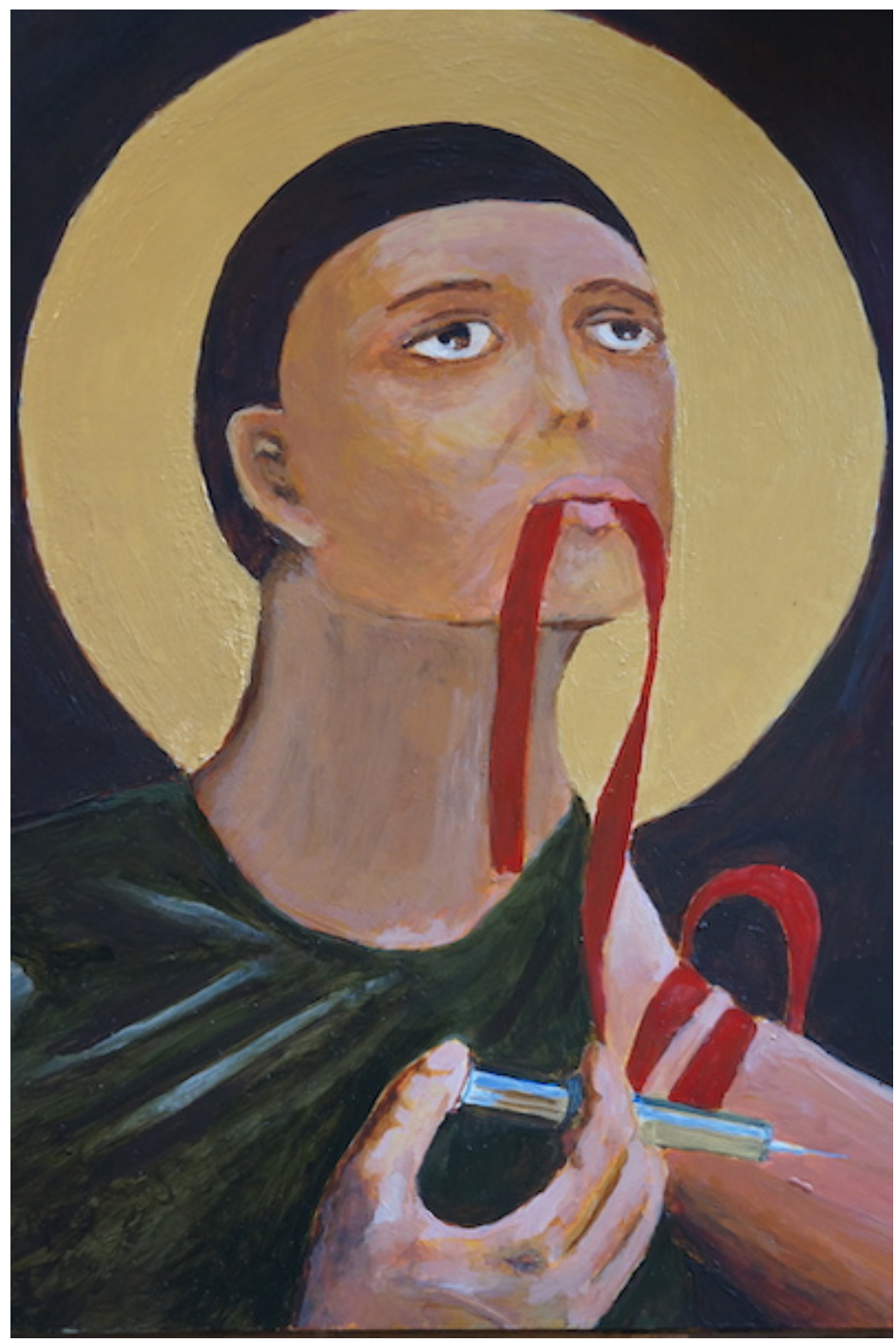

The Addict Saint. Rob Shields, Acrylic on board 2016-2019 (CC BY-NC-ND 3.0 Rob Shields 2019).
This paper sets out to discover the intangible complement of toxic or intoxicating substances that is felt through their effects. It begins from the qualities of the toxic and considers the historical conception of the toxin as an external substance that brings benefit and illumination but is lethal in larger doses. The pursuit of transcendence is a common benefit illustrated in the addicted and the saintly. They share a pursuit of the 'intoxic,' a force that mediates between the body and transcendence, whether spiritual or social. It is also a characteristic effect of the toxic and inebriating materials.

The toxic and toxicity involve elements of intensity, emergence, and interactivity. These three aspects point to a fluid, unstable aspect of toxins and hint at the social and creative, as well as medical benefits of substances consumed in below-toxic doses. To begin, let us treat toxins as material and the adjective, toxic, as a class of agents, thus as an abstract category. Toxins are well known to have different effects at different doses. Conversely, any beneficial drug becomes toxic above a certain dosage. However, toxicity is also emergent and raises questions of Becoming: exposure over time 
to toxins may result in their accumulation to toxic levels. Toxicity is thus an effect, a real but intangible change from some status or over time. However, it also involves a capacity to be toxic, thus implying a virtual, ideal-real quality of toxicity that I will examine under the label of the 'intoxic,' below. ${ }^{[1]}$

What creates toxicity? Contact with toxins or their use is a matter of a calculation of risks and benefits. We may attempt to benefit from producing and consuming, or even simply admitting toxins into our environments. However, we run a risk of developing diseases that manifest at a much later date. Toxicity has an emergent temporality. This is a key quality of many toxic and carcinogenic substances. The effect of toxicity is also contextual. For example, we don't tend to think of X-rays as toxic, but exposure to them is both helpful in diagnosing ailments and dangerous in causing a certain percentage of cellular mutations in a population. Further, benign substances may become toxic in combination with other substances. Their interaction alters their potency. Intensity and interactivity are thus aspects of toxicity as the effect of relations that may be either beneficial or toxic, or both. Quantitatively, toxicity results from the dose, but qualitatively, toxicity is contextual. It arises in conjunction with circumstantial and mediating factors.

Much of this is understood according to the probabilities of risks and benefits, blurring and extending the categorical quality of 'toxic' from being a broad abstract class of phenomena that are possibly toxic to the cases of predictable, actually probable levels of toxicity. It is not simply a question of material effects, but the otherwise abstract class or category of toxicity is an effect or result of other capacities or qualitative interactions and forces. The ambiguous quality of these component elements of the toxic - at times material, at other times predictable but still latent, and still at other moments abstract, 'possibly toxic'-is also echoed in the manner that discussions of toxic substances and wastes blur the line between the rational and affective. Buell (1998) notes:

Contemporary toxic discourse effectively starts with Rachel Carson's Silent Spring (1962). In contemporary toxic discourse, furthermore, victims are permitted to reverse roles and claim authority. It is plainly a discourse of allegation rather than of proof. Its moralism and intensity proceeds in good part precisely from the awareness that its charges have not yet been proven, at least to the satisfaction of the requisite authorities. (Buell, 1998: 659)

As an organizing concept for victims' discourses, allegations of moral corruption, unethical behaviour and social and environmental injustice, the toxic and the toxicity of unethical behaviours are part of the language of moral claims. While I will not offer a history of pollution or of the toxic, the term is normatively linked to the noxious and dangerous in European and North American discourses, in particular as part of the legacy of Rationalism, the Protestant stress on Reason and attentive diligence. Not only is the normative discourse related to Prohibitionist movements against alcohol, cannabis and other intoxicants, but it has been central to hygiene and health movements and efforts to improve public health. This normative discourse offers an alternative logic against prevailing authorities, science, prevailing common sense, what is legally permitted, expert risk assessments, and defensive responses. Buell (1998) argues that the fear of a poisoned world is being increasingly debated, debunked, and reiterated from many disciplinary vantage points. However, toxicity is rarely assessed as discursive as well as material. Nonetheless, 'the sociological evidence of the emergence of toxicity as a widely shared paradigm of cultural self-identification and of toxic discourse as a commensurately influential force continues to accumulate' (Buell, 1998: 665). 
As a portal to the incommensurable, toxicity is influential in discourses of allegation (for example, of pollution). It steps around logic and reasoned argument to insinuate passion and affect into public discourse. The implications of Buell's observation about the force of the toxic in discourse are important in the contemporary context of 'posttruth' media discourse. The reversal of authority from the externally positioned, objective expert to an implicated, involved and bodily compromised victim or community can be analysed using the image of a folding over of logic to induce reversals and the possibility of jumps between strict deductive steps.

An impasse is created which makes one confront the irreconcilable poles of logical and affective reason. Impasses trouble methodical approaches and claims to knowledge as they force an unlearning of taken-forgranted certainties (Berlant, 2007; Stewart, 2013). What is this discursive force of the toxic? It is not only a condition or victim status, but something that troubles both evidentiary logic and calculative, rational discourse. It therefore implies a challenge to the entire edifice of established and legitimated logics. These logics are not only the logical results of scientific evidence but extend to trust relations and power structures. It presents a fourfold ontology that draws on elements that are actually real or material, that are real but intangible, on abstract representations of the possible, and on calculations of 'actually possible' or probable.

To the extent that the toxic concerns an interactivity, it involves relations that may be emergent or latent and whose intensity reflects an imbalance of power. Discussions of the toxic easily open up issues of the ethics of power relations inherent in the toxic as an effect of an externality, a substance consumed by a body-perhaps unknowingly. To the extent that toxins are created by others, these discourses also bear on questions of the justice of the relationship between the creator or provider and the consumer or victim of the toxic.

The toxic is not only a paradigm in discourse but mediates and assembles collectives of those affected or at risk, of victims, or perpetrators and agents who administer toxins, and wider audiences who are witnesses (Nissen 2013). This mimetic process of assembling those who share a position against others is a form of social cleavage that crosses class lines. For example, air pollution unites the powerful and the powerless because it affects all who breathe (Beck, 1992). Toxic drugs such as fentanyl affect both vagrant addicts of opioids and wealthy recreational consumers of drugs such as street Viagra and ersatz cocaine (for example, see Lakusta, 2016).

A toxin acts a material medium in which bodies are drawn together, polarizing relationships of dependence, implication and witness. Toxicity may emerge over time or through the overuse or overindulgence in consumption or a practice. This unintended effect is often due to a reliance on the perceived benefits of the toxin. Such dependencies also characterize the toxic effect of parasites on a host. Witnesses are assembled through the affects of the loss of stability of a victim or situation. They are often a moral chorus that marks the horrors of the toxin and the hubris of protagonists who think they can control the toxic. Those implicated in the sources of the toxicity may be vilified or derive social power and prestige from their association with the benefits and danger of the toxic.

Does the source of the power of toxic discourse not inhere in its combination of intensity and its mobility, or more precisely, the apparent fluidity and reversibility of its discursive effects? The toxic is a mobility in many ways. Toxins set an equilibrium body or ecology into a dynamic, mobile, non-equilibrium state. Persson (2004) gives a phenomenology of drugs as embodied processes that reconfigure bodies and diseases in multiple ways at once 
-beneficial and detrimental to the same person at the same time. Rather than recoil or attempt to resettle the relations destabilised or set in motion by toxins, is it possible to work with the logic of these dynamics? This involves integrating both the negative sense of the toxic and its potentially useful or positive usages or effects.

Despite their ambiguity and relational qualities as media, toxins ultimately concern bodies and the health of living systems, generally organisms. This is a further essential quality of the toxic. While toxins focus the attention and behaviour of individuals aggregated into groups, this quality of a social medium requires the organic canvas of a body or bodies as a substrate on which it becomes apparent to the senses and is experienced. Intoxicated and poisoned bodies are those that have lost their agency and semblance of independent volition. The poisoned are helpless in the face of their symptoms and have no way to eliminate the toxin or avoid the effects once poisoned unless an antidote is provided from an external source. Where toxins are the material cause (and there is no doubt of their materiality), organic bodies are the material medium by which toxins are apprehended and known through their effects. I will use the term 'intoxic' to refer to this veiled quality or effect of the toxic, the way in which it is not known directly but as a set of effects in the flesh and on the mind, after it has taken effect, rather than actually and directly as a material phenomenon. Some of the effects of toxins and intoxicants are noticed, others are experienced without being remarked on. These are variable between persons so the experience varies. The toxic thus also brings a problem of knowledge, highlighting not only the vulnerability of the body once poisoned but the subjectivity and the inefficacious indirectness of knowledge as almost hindsight.

\section{Pharmakon}

Given the risk posed by the toxic, it is surprising to note that, whether in the wild or in the laboratory, 'Almost every species of animal has engaged in the natural pursuit of intoxicants,' concludes Siegel in a broad history of intoxication across species (Siegel, 2005: 114). For example, toxic angiosperms evolved chemical protection against herbivores so that their food and what is healthful (or in other cases, is beneficial, for example, as a sedative or a painkiller) is also poisonous. A toxic angiospore is, of course, pleasurable to consume. Chemicals designed to protect plants are sought by animals to procure the diversions of transcendence. Drug users and participants in rituals may also seek transcendence (Nissen, 2013). Indeed, Derrida refers to the fetishism of drug

addiction as 'Not religion as the opium of the people, but drugs as the religion of the atheist poets' (2003:29).

Thus the famous oxymoronic sense of the ancient Greek Pharmakon, an ambiguous word meaning 'drug,' as both remedy and poison but also 'scapegoat' (Rinella, 2010). In his deconstruction of several of Plato's works, Jacques Derrida (1981: 99) offered a famous commentary on the ambiguity of writing as Pharmakon which creates an internal circularity and undecidability within Plato's texts and, more importantly, within critical understandings of rational knowledge and communication (cf. Stiegler, 2010; 2011). Derrida's description is worth recalling for his use of 'medium,' 'movements,' reference to excess ('shadow') and the entangling of material and intangible:

If the Pharmakon is 'ambivalent,' it is because it constitutes the medium in which opposites are opposed, the movement and the play that links them among themselves, reverses them or makes one side cross over into the other (soul/ body, good/evil, inside/outside, memory/forgetfulness, speech/writing, etc.)....The Pharmakon is the movement, the locus, and the play: (the production of) difference. It is the différance of difference. It holds in reserve, in its undecided shadow and vigil, the opposites and the differends that the process of discrimination will come to carve out. Contradictions and pairs of opposites are lifted from the bottom of this diacritical, differing, deferring, reserve. Already inhabited by différance, this reserve, although it 'precedes' the opposition between different effects, even though it preexists differences as effects, does not have the punctual simplicity of a coincidentia oppositorum. It is from this fund that dialectics draws its reserves. (Derrida, 1981: 127) 
An older meaning, Pharmakos, or 'scapegoat,' designated a person offered in sacrifice or sent into exile. This ritual produced a catharsis and cleansing in times when the polis suffered crisis or calamity. Persisting as an annual ritual on the first day of Athens's festival of Apollo, two male Pharmakoi were led outside of the city walls not knowing their exact fate-to be thrown off a cliff, burned, beaten or exiled, literally or symbolically. This political, ritual and sacred ceremony of ambiguity purified the interior of the city, the polis. The scapegoats, Pharmakoi, 'produce' the effect of cleansing (cf. Liddel-Scott-Jones Greek-English Lexicon). We might speculate that the terrifying ambiguity of not knowing their fate is an important aspect of this ritual. The catharsis of the ritual expulsion of the Pharmakoi is an example of the positive face of an otherwise negative phenomenon. Girard (1977) finds in this cathartic release a generative violence that assembles the rest of the people into a community; that is, they share in the collective guilt for the arbitrary violence.

In as much as the negative impact is also accompanied by a positive impact, " $\mathrm{t}$ ]he inescapable implication of these facts is, of course, that "saying no" is not really an option: intoxication is a biological imperative quite comparable, if not identical, to the other two: hunger and love. So what really moves the world is a triad: get fed, get laid, get high' (Siegel, 2015: 114). Milton (1644), in his Areopagitica noted the principle that goodness and badness do not inhere in things themselves but are consequences of how they are used:

They are not skilful considerers of human things, who imagine to remove sin by removing the matter of sin; for, besides that it is a huge heap increasing under the very act of diminishing, though some part of it may for a time be withdrawn from some persons, it cannot be withdrawn from all, in such a universal thing as books are; and when this is done, yet the sin remains entire. (Milton, 1644: np)

How a thing is used is not simply a functional matter but is relational. This is a question of the relations entered into with the Pharmakon. Effects arise from the capacities that these relations produce. For example, on the one hand, bodies have varying abilities to metabolise Pharmakoia, and on the other hand, these have different capacities to affect bodies.

Toxins are conceptualized and represent a mode of externality and 'outsidedness' (cf. Bakhtin, 1973 Vnenakhodimost). The external, destablising source of the toxic becomes clearer in the etymology of the term that follows an objectifying and externalizing logic to imagine the strike of an arrow that poisons a prey. Outsidedness reminds a body of its vulnerability and also the limits of its ability to know and command its environment, sparking the social need for collaboration.

'Toxic' (adj.), 'containing poison' (potare 'to drink'), a deadly potion or substance that is consumed, was imported from the French toxique (1690s) and the ancient Greek toxikon ('for use on arrows') and Persian taxša ('bow'). 'Toxin' (noun) appears to be only a late nineteenth-century addition to English. Thus, where Shakespeare has 'poisons,' 'potions' and 'venom,' he does not deal in the pharmako-logical ambiguity of toxins or the toxic. Instead, he offers the antidote of critique-as-cure:

...Give me leave

To speak my mind, and I will through and through.

Cleanse the foul body of the' infected world,

If they will patiently receive my medicine

(Shakespeare. As You Like It II, vii, 47-61 Online)

\section{The Intoxic}


In contrast to the Mediterranean world's sense of the toxic as a poisonous drink since before the time of the Greek physician Galen (2 CE), I would like to turn to the Germanic terminology for poison that is the equivalent to the English 'gift' from Old High German and Scandinavian sources, gift, a giving or prescribed dose (see also Galen, 1821-33).

Where Western pharmacology follows the Mediterranean episteme that labels toxins as destructive, both history and Indigenous ritual and medicinal use of hallucinogens treat them as not only curative but also enlightening. We can treat the stem 'intoxic' as a label for this aspect of the toxic Pharmakon as potential and capacity. The intoxic is not the opposite but the complement to the toxic-found, for example, in its pleasures and importance as a source of liberation from the mundane world of need and imposed routine. However, transcendence alone does not exhaust the intoxic as a category. It is the capacity of psychotropic transcendence as an emergent experience and which is described through its representations such as texts on drugs, addiction, and pharmacological categories, and which is known through the experience of actual intoxication.

Other elements may include hallucination or 'visions,' 'submission' to the anaesthetizing effects of intoxicants, and 'delight.' By contrast to other available terms, the intoxic does not designate outcomes: it is neither 'transcendence' as a mental experience or sensation, nor 'psychotropy' as a state of consciousness, nor 'enlightenment' as a product. It does not designate ingredients such as plants, alkaloids or other agents that produce intoxication. The intoxic does not designate other material inputs or processes such as rituals of intoxication. It is not a 'drive' per se or other metacategory. It is an intangible, a virtuality.

Considering the toxic from the vantage point of the intoxic raises new questions. Bateson (1978) points out the palliative qualities of alcohol for the alcoholic dependent on it (Bateson, 1978:317). Valverde notes that,

tales of intoxication and addiction, which in our culture are inextricably bound with either gaining the truth (in the Romantic/psychedelic model) or with losing it (in the sobriety paradigm) have had and continue to have a popularity that is not necessarily related to the popularity of the substances themselves. Either positively or negatively, a privileged connection is established in these texts between drug taking and truth-telling. (Valverde 2002:8)

The intoxic manifests itself affectively in delight in the experience of non-equilibrium states of mind and body that offer a promise of insight, transcendence, liberation or even just distraction. It involves risk, submission to the external agency of the toxin, and the subjugation of the critical subject or ego in the name of pleasure, enlightenment and transcendence.

The intoxic is manifest in the experience of transcendence as a 'going beyond,' 'surmounting,' 'transgression' of the everyday present and presence.

\footnotetext{
Transcendence in the largest sense is a sensation of pleasure consisting in--what, exactly? The usual terms and descriptions are nicely paradoxical: intoxication or mystic vision can be 'exciting' or 'stupefying'; it can permit us to 'escape from ourselves' and contact a 'supernatural' world; or it can plunge us into ourselves, revealing the 'god within' (the literal meaning of 'entheogenic'; the earlier term was 'psychedelic'-making visible the soul). But whatever direction we travel (recall the usual name for such transport: 'trip'), inside or outside, we are in either case changing places-going somewhere else. In other words, what is common to these paradoxical descriptions is the '-else,' the fact of alteration itself. Another term for the substances that produce it is more inclusive and precise: 'psychotropic'-turning, altering the mind or soul, i.e., our state of consciousness. (Waswo, 2016)
} 
An intoxicated loss of sense of self may offer an encounter with or experience of the dependence of the individual on the environment. Transcendence offers a potential realization of the socially mimetic and dependent quality of the individual subject, and their sense of monadic isolation (Callois, 1984; Tarde, 1890). While the subject may lose their sense of self, their corresponding, oceanic, sense of transcendent relatedness represents an expansion of both the capabilities of cognition and position of cognition. This experience can later be remembered within the narrower demands of everyday life and the strictures of 'cognitive normality.' I will not offer a history of social uses of transcendence. Suffice to point out that the outcome of the intoxic is not simply a release of endorphins but intensity and interaction between self and other, inside and outside, mundane and extraordinary. It is not simply behaviour but a social activity that is interactional and can be a source of visions for social change.

This relational quality makes the intoxic more difficult to pin down than the toxic as a category or toxins as material. While the toxic nearly always refers to a material object (toxin, poison, dose, arrow), whether toxin, toxic actions or an intruder, by contrast the intoxic is a force, an intangible virtuality that is 'real but ideal' and refers to a capacity or relation, as in the sense of 'to intoxicate.' It is neither an ideal such as a category nor a classification of intoxicants that one could image naming 'intoxics;' nor is the intoxic a probability, risk or perfomativity related to a level of toxicity.

The focus of this article is on the hallocinogenic and narcotised intoxication. However, the intoxic provides a bridge to think from chemically induced psychotropy to other forms of stimulants and hyperstimulants. Sports, meditative practice, collective action, play, the carnivalesque and even immersion in an activity such as music or reading have a similar link to the intoxic.

'Say what you like about self-medicators - we're people who earnestly seek heaven. To say that we do it wrong wouldn't be wholly correct,' comments one writer (Lindenman, 2011). We might suggest that the intoxic gives access to an experience of the incommensurable that is independent of a functional goal and thus exceeds representation. The intoxicated entertains a relation to the Pharmakon that does not conform to utilitarian rationality of cost versus reward, risk versus benefit. That is, the intoxic exceeds the dualism of the Pharmakon. This supplement or excess implies that to be intoxicated is to stand at the precipice of the unrepresentable. It challenges conventional notions of the subject and will (Valverde 2002). There is a monstrous, unnameable quality to the experience and practice. This is the horror of the position of the addict.

Why horror? The excess of intoxication is a form of ex-stasis, the ecstatic. This excess defies the everyday basis of language and meaning-making. The challenge of representing the intoxic as an outside to the everyday falls to creative poets, artists and performers who may communicate by allusion and demonstration rather than representation. In the absence of their creative mediation, the intoxic is formless in its unrepresentability. Horror, in this case, comes from the monstrosity of formlessness that is at the base of the challenge to conventional representation.

As such, the intoxic shares in the logic of the incommensurable, of the sacred and of sacrifice. But, should the intoxicated or drug-addicted not thus be treated as not only self-sacrificing but in their relation to an incommensurable-are they not also to be sanctified? In The Accursed Share, Bataille (1988) understands this urge, reaching beyond the mundane, in explicitly political terms: 
If the worker treats himself to the drink, this is essentially because into the wine he swallows there enters a miraculous element of savour, which is precisely the essence of sovereignty. It's not much, but at least the glass of wine gives him, for a brief moment, the miraculous sensation of having the world at his disposal. The wine is downed mechanically (no sooner swallowed than the worker forgets it), and yet it is the source of intoxication, whose miraculous value no one can dispute. On the one hand, to take advantage of the world, of the world's resources, as does the worker drinking the wine, partakes in some degree of the miraculous. On the other, it is the substance of our aspirations. We must satisfy our needs, and we suffer if we fail, but where the necessities are at stake we are only obeying the animal injunction within us. Beyond need, the object of desire is, humanly, the miracle; it is sovereign life, beyond the necessary that suffering defines. (Bataille, 1988: 199)

Any appreciation of the intoxic requires a position that avoids the dualism of positive and negative. Beyond good and evil, Bataille (2015) argues that a true ethics takes place 'independently from a moral goal' (4-5), in that it can have no future orientation. The intoxic is an ethical force. It is a pure Simmelian sociality, a communitas and a loving engagement with intoxicants that depends on the negativity of intoxication to indulge its positive effects (Shulgin, 1995). The toxic thus violates or shortcircuits the dualisms that Western civilization has been built on and gives rise to a corresponding horror at the collapse of categories. Bataille (2016) develops exactly this position as a conscious contradiction, an irresolvable antagonism between antitheses, each of which are impossible extremes (cf. Bataille, 2016: 140ff.).

The refusal of the right-wrong distinction of moral reason means any resolution of the dilemma of the Pharmakon or the excessiveness of the intoxic into an either-or dualism is self-defeating. The result is to defy logical structures that demand this distinction of $a \neq b$. The resulting paralogical structure is not the fallacious position of a mistaken identity but rather contests the basis for making the distinction between a legitimated knowledge and an illegitimate or repressed knowledge. There is some similarity and crossover between Derrida and Lyotard, who trade in the same terms, differend, 'that which does not have the punctual simplicity of a coincidentia oppositorum' (Derrida, 1981: 127; compare and contrast Lyotard, 1988) but spurs further dialectic. This can be understood in a minor version of paralogy as simply the ongoing creation of meaning. For example, this is reflected in the way one comment to a person inspires them to say something, possibly unrelated, in return. The ongoing process binds us to the process of dialogue in an ongoing spiral of new ideas (cf. Shawver, 1996). Lyotard is one recent philosopher who has explored the possibilities of paralogisms as a move beyond Habermasian universal consensus via local exceptions and imaginative recasting of ideas, such as with puns and jokes or deliberate new (mis-)uses. This can be seen to be productive of new concepts, new horizons for thinking and living. Lyotard (1984) identifies paralogy with a postmodern condition in thought. Fritzman (1990) describes paralogical thought as 'imaginative moves which directly contest the procedural rules that claim to regulate and adjudicate conflict' based on the necessarily local, contextual character of dialogue (380).

Drawing on Lacan, Braunstein argues that the use of intoxicants permits a form of 'chemical jouissance' (1996:4). Drugs are 'a method by which the subject subtracts him -- or herself from the process of symbolic exchange' (Braunstein, 1996:1). In the case of drugs or other intoxication, this is 'the result of a decision, a choice. It is something that permits a type of experimental connection with jouissance and that produces a short circuit in relation to the Other and the Other's desire' (Braunstein 1996:1). Intoxication is a rejection of social demands by suspending the subject creating an anonymity to the self and to the Symbolic order. Is intoxic 'jouissance' an attempt to transgress limits imposed on enjoyment or pleasure, that is, even beyond the limits of meaning and the subject, 'beyond the phallus' (Mitchell and Rose, 1982:145; Lacan, 1999)? The drug or intoxicant becomes an autoerotic fetish object of need that even substitutes for the relational demands of 
sexuality. 'Confronted by the mark that is imposed on them by an ideal, addicts will exert their will in the form of the body deprived of vital reactions, a simple metabolic machine without desire, a fantastic and fantasmatic denial' (Braunstein, 1996:6).

\section{Saintly Addicts, Sacred Addiction}

The previous sections have sought to establish the intoxic as a pharmako-logical outside, the epistemological and ontological force rather than the material substance of the toxic; this next section examines its long and diverse history of appropriation as an interface to insight and social structure. Institutionalized within ritual forms of intoxication (Guerra-Doce, 2014), the intoxic ruptures the limits of ecological continua and equilibria as the intangible complement of the toxic material. This is not only a spatial relation to an exterior but a temporal operation that changes the poisoned or inebriate's relations with the present, for the toxic is dependent on time (frequency of administration) as well as quantitative dosage. It also has a limited temporality, its effects fading as the body eliminates toxins that have been metabolised. The effect is to create a liminal time-out from everyday life that is not sustained, although it can be integrated into cultures through repeated routines. This temporal-spatial topology further defines the intoxic: a toxin is external and enters the space of the body, it is not immanent nor an autoimmunity, and untreated it is terminal. But, by contrast, the intoxic establishes a temporary but repeatable relation between the body interior and the external context or world. Like a natural season, the intoxic can become a psychosocial rhythm of periodic liminality (Turner, 1969) or a suspended, time-out-of-everyday-time.

Hegemonic relations establish the negative, accursed subject-position of the Addict. Additionally, nothing precludes the intoxic existing alongside self-delusion, narcissism or vanity. The figure of the Addict as a subject position is not only a cultural abstraction, but a sociological and medical category -- an undoubtedly abject one. This position is embedded in materiality, in economic processes, and social categories and norms. Rather than chosen, the addict may seek the intoxic but find themselves chained into these categories and materialities that include the black market for illegal drugs, the risks of street drugs, and the stigma of loss of role in formal institutions of work and family. My argument is not that the intoxic is separable from these material conditions in anything other than an analytical sense, but it allows us to approach it anew.

In Western cultures, addicts are often treated as indulgent escapists from the challenges of everyday life or as weak dependents on intoxicants (see the critique in Nissen 2002). They are morally toxic. Alcohol, for example, may impede the struggle to follow a moral life, even if by relieving the moderate drinker of everyday stress for a moment. The ruination of addiction is that it not only enslaves the body, but reduces the transcendent moment of the intoxic. The desire for this 'miracle' becomes an enslaving, omnipresent demand and irresistible need. Labelled 'toxicomania' by psychiatry, the Addict was constructed as a nineteenth century individual 'type' whose lack of self-control and sensuousness was to be policed by visually profiling, and, more recently, by genetic phenotypes of addictive personalities. The situation of the addicted is tragic and transitive: in it we see the possible effects of all intoxicants. As tragedy, the Addict plays out a fall from grace. They reduce the heroic dream of exceeding the conditions of life to the pathos of enslavement. Desire for the sublime, the divine excess beyond relations of existence, causes them to lose their sovereignty as human. Here may be one reason why addicts are both stigmatized and shunned. Medicalized under capitalism as unproductive and incapable, the dysfunctional inebriate disrupts the flow of social normalcy. In addition, they impose an ethical demand, calling on our care for their condition and imposing social costs as a result. 
However, the undecidability and fraughtness of the Pharmakon requires that the toxic be treated with veneration, with ritualized rigour that gives its practices a quasi-religious quality. Christian tradition recognizes intoxication, even while it has preached against it. Two Catholic Saints of the intoxicated, both addicts, include St. Mark Ji Tianxiang and St. Maximilian Kolbe. I wish to explore a different position from the $19^{\text {th }}$ century notion of drugs as inducing a state of devilish narcotic possession (Cole 1895) or as necessary to an addict's everyday life or basic, mundane functioning as examined by Richard English (2016) in the novels and semi-autobiographical work of Alexander Trocchi (1998) and William Burroughs (1977). In intoxication and addiction, there is an engagement with the incommensurable that is the deeper subject of Christian mystic tradition and iconography. The seeker of transcendence who enters the tragic, but often ends in the pathos of addiction, is the figure of the intoxic -- a reminder not only of the humanity and material suffering of the Addict but of our mutual entrainment together with them in the logic and force of the intoxic. Beyond mere escapism, do not addicts share in the saints' search for transcendence from the mundane, insight, and truth? Could addiction not be treated as a symptom of a sacred questing? This would challenge the secular economy typical of contemporary societies.

Perhaps the Addict is not unfit but holy - or perhaps both? Possibly this provides a contrarian insight into what it means to live in hell? Within the habits of the Addict and the experience of intoxication lies an alternative to the productive rationality that turns bodies toward relations of maximum utility under capitalism. Is the Addict not only holy but one who should be understood as resisting social and economic norms?

Rather than a 'reserve' or mobility of 'differance,' in Derrida's terms (1981; 2003), or a conceptual 'move' to open the boundaries of dialogue and interaction, in Lyotard's terms (1988), the intoxic is a force that assembles, mediates and inter-relates ethically and socially as well as through the materiality of the toxin. Like the Pharmakon, it is neither necessarily positive nor negative. However, the intoxic is unlike the Pharmakon in that it is a virtuality, limited to the force of the phenomenon. The intoxic is not material, abstract or probabilistic but a capacity. As such, the focus on the intoxic highlights the operation of power between and into bodies whether abstractly in discourse or actually in its effects of social engagement and toxicity.

\section{Refection: The Addict Saint - Addiction and Transcendence}

The etymology of the toxic indicates an intense external force, a 'giving' that fundamentally alters the status of the receiver, destabilising the healthy functioning of the body. As a gift, as giving, the toxic is relational and presumes not only the effect of the toxin, but also the agency of the giver of the dose whose power or authority overcomes that of the subject. This image of the intoxicated as victim is contrasted by the force of the intoxic as flesh contrasts with vision.

Their emergent qualities in combination with other substances pointed this article toward the fluid, mobile and ambiguous and interactive qualities of toxins as Pharmakoi. They are used for both rational and affective ends in complex calculations of risk and benefit. Discursively they appear as paralogical, challenging simple rational assessments of risk with an affective politics that reverses authority from the scientific to the terms and contextual vantage point of the affected body. This position explores the intoxic as a novel element of intoxication and psychotropy. There are elements that touch on themes such as the homo sacer in the sense of not only the 'sacred' but also in the sense of the outcast Pharmakoi. But while that exile may be imposed, the intoxic, as a compelling force leading to a self-withdrawal into the world of addicts, points toward Hermetic and mystical traditions. In a further discussion, I would turn to the Thomas de Quincy's 1821 Confessions of an English Opium 
Eater, and the work of Tennessee Williams, John Cheever, and Raymond Carver (see Simpson and Buzby 1983) and others (see Laing 2014; English 2016). But in addition, the history of art contains a significant trove of not only representations but also reflections - think of Caravaggio -- on the intoxic and its cultural, social and epistemological roles.

Toxins reveal a fluid quality that exceeds the merely material and pose epistemological challenges to logic and reason based on an ontology of material facts alone. Fundamentally, the toxic is a question of the body and its vulnerability to invasion, penetration and occupation. Yet, this potential for reconfiguring social alliances indicates a less-analysed, relational aspect of the toxic as a medium through which differentiated and opposing collectives are drawn together (Nissen, 2013). Victims, the intoxicated, witnesses, health professionals, and perpetrators share common positions thanks to the toxin. Therefore, not only is the toxic in discourse, but also it has mediating qualities itself. It has assembling, constitutive power on bodies, recalling the catharsis of the expulsion of the Pharmakoi.

The intoxic is the gift of the toxic, a complement to the physiological elements of the toxin. The intoxic is an intangible that puts the materiality of the body into a non-equilibrium state, an ex-stasis or mobility that transcends the mundane and breaks the bonds of social and economic governmental rationalities. It refers to a capacity or relation, creating a second mediating moment at which the social is split and distinct communities assembled in relation to the poisoned body, to the Addict. Witnesses, victims, perpetrators ... these are recast beyond the dualism of positive and negative. This allows the toxic to function paralogically: sovereign life displaces discipline and governance; the non sequitur complement in discourse opens new dimensions for engagement.

\section{References}

Bakhtin, M.M. (1973) Problems of Dostoevsky's Poetics. Ann Arbor, Michigan: Ardis Press.

Bataille, G. (1988) The Accursed Share: An Essay on General Economy. New York: Zone.

-. (2015) On Nietzsche (trans. Kendall). New York: SUNY.

—. (2016) La Limite de l'utile. Paris: Éditions Lignes.

Bateson, G. (1987) Steps to an Ecology of Mind: Collected essays in anthropology, psychiatry, evolution, and epistemology. Northvale, N.J.: Aronson.

Beck, U. (1992) Risk Society: Towards a New Modernity. London: Sage.

Berlant, L. (2007) "Starved.” South Atlantic Quarterly 106:3 (Summer): 433-444.

Braunstein, N. (1996) “Drug A-diction.” Journal of the Psychoanalysis of Culture and Society 1(1): 167-170.

Buell, L. (1998) “Toxic discourse.” Critical Inquiry 24(3): 639-665. 
Burroughs, W. S. (1977) Junky (1st complete and unexpurgated ed.). New York: Penguin Books, 2008.

Cole, H. (1895) Confessions of an American Opium Eater. Boston: Earle.

Callois, R. (1984) “Mimicry and legendary psychanaesthesia." October 31 (Winter): 17-32.

De Quincy, T. (2008) Confessions of an English Opium-Eater. Oxford: Oxford World Classics.

Derrida, J. (1981) “Plato’s Pharmacy.” In: Johnson B (trans. Dissemination. London: Athlone, pp. 61-172.

-. (2003). The rhetoric of drugs. In: Alexander A and Roberts MS (eds.) High Culture Reflections on Addiction and Modernity. Albany, NY, USA: State University of New York Press, pp. 19-43.

English, Richard. "Theories of Opiate Addiction in the Early Works of Burroughs and Trocchi." CLCWeb: Comparative Literature and Culture 18.5 (2016), doi:10.7771/1481-4374.2931. Accessed Nov. 152019.

Fritzman, J.M. (1990) "Lyotard's paralogy and Rorty's pluralism: Their differences and pedagogical limplications." Educational Theory 40: 371-380.

Galen (Galenus Medicus) (1821, 33) Corpus Galenus Medicus. Ed. C. G. Kühn, Leipzig; H. Diels et al (eds.), Digital transcription in Thesaurus Linguae Graecae - Abridged. University of California Irvine. Retrieved June 24, 2017. stephanus.tlg.uci.edu/abridged.php

Girard, R. (1977) Violence and the Sacred. Baltimore: Johns Hopkins University Press.

Guerra-Doce, E. (2015) "The origins of inebriation: Archaeological evidence of the consumption of fermented beverages and drugs in prehistoric Eurasia." Journal of Archaeological Method and Theory 22(3): 751-782.

Laing, O. (2014). The Trip to Echo Spring: On Writers and Drinking. New York: Picador.

Lakusta, D. (2016) Two men charged after Edmonton police dismantle fentanyl lab, seize $\$ 435,000$ in drugs. CBC News. 7 January. cbc.ca/news/canada/edmonton/two-men-charged-after-edmonton-police-dismantle-fentanyllab-seize-435-000-in-drugs-1.3393475.

Liddell, H.G. and Scott, R. (1940) A Greek-English Lexicon, I. Authors and Works (H. S. Jones, Ed.) (Tufts Online Edition) Oxford, Clarendon Press. Retrieved from perseus.tufts.edu/hopper/text? doc=Perseus \%3Atext\%3A1999.04.0057\%3Afrontmatter\%3D1\&force=y

Lindenman, M. 2011. 'The Addict Saint.' Blog. Diary of a Wimpy Catholic (blog). September. patheos.com/blogs/diaryofawimpycatholic/2011/09/the-addict-saint/. Accessed Mar. 62017.

Lyotard, J-F. (1984) The Postmodern Condition: A Report on Knowledge (trans G Bennington and B Massumi). Minneapolis: University of Minnesota Press. 
—. (1988) The Differend. Minneapolis: University of Minnesota Press.

Milton, J. (1644) Areopagetica: A speech of Mr. John Milton for the liberty of unlicenc'd printing, to the Parliament of England. dartmouth.edu/ milton/reading_room/areopagitica/text.html. Accessed Dec. 152018.

Nissen, Morten. 2002. "To Be and Not to Be." Outlines. Critical Practice Studies 4 (2): 39-60. tidsskrift.dk/outlines/article/view/5149. Accessed Oct. 12019.

Nissen, M. (2013). "Recognising Life - A Study in the Atheist Micro-Bio-Politics of Drugs." Subjectivity 6 (2): $193-$ 211.

Persson, A. (2004) "Incorporating pharmakon: HIV, medicine, and body shape change." Body \& Society 10(4): 4567.

Rinella, M. (2010) Pharmakon: Plato, drug culture, and identity in ancient Athens. New York: Lexington Books.

Seigel, R. (2005) Intoxication: The Universal Drive for Mind-Altering Substances (New edition). Rochester, VT: Park Street Press.

Shakespeare, W. As You Like It. Boston: Massachussets Institute of Technology. shakespeare.mit.edu/asyoulikeit/full.html

Shawver, L. (1996) "Paralogy," Andy Lock. Theory Lectures blog. 14, Auckland: Massey University (Sept 25). massey.ac.nz/ alock/theory/l14.htm Accessed Dec. 152018.

Shulgin, A. and Shulgin, A. (1995) Pihkal: A Chemical love story. Berkeley: Transform Press.

Simpson, M., and Buzbee, L. (1983). "Raymond Carver, The Art of Fiction No. 76." The Paris Review, Summer (88). theparisreview.org/interviews/3059/raymond-carver-the-art-of-fiction-no-76-raymond-carver. Accessed Nov. 152019.

Steigler, B. (2011) Distrust and the pharmacology of transformational technologies. In Zülsdorf TB (Ed.) Quantum Engagements. Heidelberg: AKA Verlag, pp.27-39

Stewart, K. (2013) "The achievement of a life, a list, a line." In Long NJ and Moore H (eds.) The Social Life of Achievement. New York: Berghahn Books, pp.31-42.

Stiegler, B. (2010) What makes life worth living: On pharmacology. Cambridge, UK: Polity.

Tarde, G. (1890) Les Lois de l'imitation $2^{\text {nd }}$ edition 1895. Paris: Félix Alcan.

Trocchi, A. (1998). Cain's Book. London: John Calder.

Turner, V. (1969) The ritual process: structure and anti-structure. Chicago: Aldine. 
Waswo, R. (2016) 'A Theory of (Almost) Everything.' Critical Inquiry (blog). 2019.

criticalinquiry.uchicago.edu/a_theory_of_almost_everything/. Accessed March 11 2016).

\section{Notes}

1. Thanks to the anonymous referee for comments, to Prof. Donia Mounsef, my symposium commentator, and to colleagues, participants and the organizers, Prof. Sourayan Mookerjea and Dr. Anne Winkler, of the Toxic Media Ecologies symposium organized by University of Alberta Sociology's Intermedia Research Studio, March 2016 and March 2017 and an exhibition under the same title at Latitude 53 Gallery in Edmonton Alberta.

\section{Cite this Essay}

Shields, Rob. "The Force of the Intoxic - The Addict Saint." Rhizomes: Cultural Studies in Emerging Knowledge, no. 36, 2020, doi:10.20415/rhiz/036.e03 